DOI: $10.1515 /$ rpp-2017-0046

Doctor of Pedagogical Sciences, Full Professor, VITALIY TRETKO Khmelnytskyi National University Address: 11 Instytutska St., Khmelnytskyi, 29016, Ukraine E-mail: tretko@hotmail.com

$\mathrm{PhD}$ in Engineering, Associate Professor, YURIY VASHKURAK

Lviv Polytechnic National University Address: 12 Stepana Bandery St., Lviv, 79000, Ukraine E-mail: yu.pawluk@gmail.com

\title{
GLOBALIZATION OF NANOENGINEERS' PROFESSIONAL TRAINING: FOREIGN EXPERIENCE
}

\begin{abstract}
Conceptual bases of globalization influence onto engineer education in the field of nanoelectronics as well as formation of global skills necessary for life and work in a globalized society have been considered. Modern state of incorporating the global dimension into the process of future nanoelectronics engineers' learning has been analyzed. Key skills and conditions of providing connection between results of learning and the global dimension in the engineering education have been defined. Possibilities of the global dimension realization (elaboration of new methods and approaches), integration of the education content on the principles of consistency and interdisciplinary nature as well as monitoring of learning results have been suggested. Special attention has been paid to implementation of the global dimension into the engineering profession that includes three aspects: generic themes, generic skills and generic dispositions. Main directions of developing the system of engineering education in the field of nanoelectronics have been specified. It has been defined that incorporation of the global dimension into the learning process of future engineers in the field of nanoelectronics encompasses five stages: the substantiation of key skills that define global dimension in engineering education; the provision of connection between the results of learning and global dimension in engineering education; the determination of opportunities to realize global dimension (elaboration of new methods and approaches); the integration of the learning content on the basis of consistency and interdisciplinary principles; the monitoring of learning results. In the result of the carried out research it has been concluded that the basis of conceptual approaches to engineering training of future specialists in the field of nanoelectronics is the logics and the content of the "engineer" notion, specifics of engineering activities in the field of nanoelectronics, as well as their functional duties in the context of globalization challenges. The process of introduction of the global dimension into the content of engineering programs in nanoelectronics encourages the development of an engineer's personality at all the levels individual, national and global.
\end{abstract}

Keywords: engineering education, nanoelectronics, global dimension, key skills, incorporation, implementation.

\section{INTRODUCTION}

Under the conditions of globalization of social-political and social-economical processes, development of nanoscience and nanoengineering, which symbolize the beginning of a new 
millennium, higher engineering education requires considerable changes aimed at professional training of a new generation of engineers. Prospects of intellectual capital investments into future development of nanotechnologies cause the necessity to increase the quality of future engineers' professional training, particularly in the field of nanoelectronics.

During last decades famous international organizations were involved into the reformation of engineering education and the priority directions of their activities were transnationalization of engineering education, ensuring quality of this process, substantiation of innovative approaches to engineering training and certification.

Because of a lack of any systemic scientific research in the professional training of future engineers in the field of nanoelectronics the need to study specifics of professional training of a new generation of engineers, capable of work and life in a globalized society, is especially urgent.

\section{THE AIM OF THE STUDY}

The aim of the article is to carry out analysis of globalization influence onto engineering education in the field of nanoelectronics.

\section{THEORETICAL FRAMEWORK AND RESEARCH METHODS}

Analysis of scientific, analytical and informational resources testifies that scientific aspects concerning problems of globalizing and integrating processes in higher education are currently the subjects of active study of home scientists (V. Andrushchenko, L. Hrynevych, I. Zyazyun, V. Kremen, V. Luhovyi, N. Nychkalo, V. Oliynyk). Different aspects of future engineers' professional training are highlighted in the works of A. Dyomin, O. Dzhedzhula, O. Kovalenko, M. Lazaryev, E. Luzik, V. Oleksenko, V. Petruk, O. Romanovskyi, P. Yakovyshyn and other Ukrainian researchers.

Elaborations of foreign scientists are of special interest (C. Ainger, J. Biggs, D. Bourn, E. Bruun, R. Evans, R. Fenner, G.Gerborn, P. Gray, C. Griffin, J. Holford, N. Jackson, P. Jarvis, C. Lambert, A. Pattil).

To fulfill the aim of our research a complex of interrelated methods has been used, namely: systemic-paradigm, structural-functional, interpretational-analytical, and prognostic. Methodological basis of the research is the main provisions of cognition theory, general scientific approaches and principles.

\section{RESULTS}

The emergence of the "globalization" term is related to the name of an American sociologist J. Maclin, who first used it in 1981. In the middle of 80 s the concept of globalization became widely spread. A British researcher R. Robertson mentioned that the concept of globalization refers both to the compression of the world and to intensification of the world realization as a whole and as a definite global dependence, as a global unity in the $20^{\text {th }}$ century.

Firstly, this term was used only in economics, but gradually spread to all social sciences. Nowadays globalization is interpreted as a "complex notion, which includes a range of processes that occur simultaneously" and has some "dimensions", the most notable and important of which are globalization of market, globalization of information and globalization of education (Bourn, 2008).

The influence of globalization onto engineering education is caused by a number of factors: development of global economics, development of information and communication technologies which objectively cause the possibility of integration processes in educational systems at regional and global levels, aspiration of the world community to form new global values in modern conditions - values of universal culture, among which the 
dominant ones must be not the power of the strong and the rich but humanity, tolerance, respect to representatives of other cultures, nations, races, religions, inclination to cooperate with them, mutual enrichment of cultures.

In its essence globalization is a total indicator of social, political, technological, cultural and ecological problems which form nanoengineering at the global level. In a recent survey of strategic directions of the British society development to 2036 the Government of Great Britain defined three dominants of sustainable development: ecological changes and natural resources, technical-economic systems, human capital and social expectations (Fig.1) (Bruun, 2010).

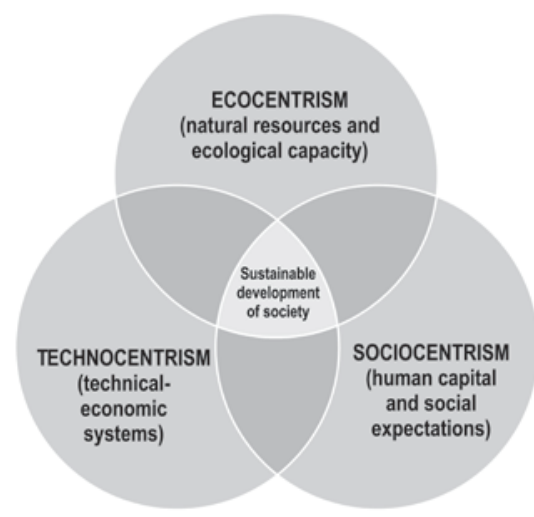

Fig. 1. From engineering to sustainable development of society

Globalization, the problem of sustainable development, use of natural resources, modern achievements of interdisciplinary researches, active development of nanotechnologies considerably influenced the change of the role an engineer in the field of nanotechnologies plays and caused the emergence of new paradigms in engineering education.

Thus, the processes of globalization in engineering education are represented in three aspects: institutional (activities of famous international engineering organizations: World Federation of Engineering Organizations (WFEO), European Federation of National Engineering Associations (FEANI), International Federation of Engineering Education Societies (IFEES), European Network for Accreditation of Engineering Education (ENAEE), European Society for Engineering Education (SEFI), International Institute for Development of Engineering Academics (IIDEA), Global Engineering Deans' Council (GEDC) and others), conceptual (implementation of global dimension into the content of engineering education) and procedural (implementation of global dimension into educational process, elaboration of standards for quality of engineering education).

Definition of the engineer's profession must correspond to definite conditions and it constantly undergoes considerable changes. First of all, engineering profession presupposes the ability to analyze and effectively solve problems of different scale, which are related to elaboration, production and introduction of products, systems and services in a competitive environment and, if necessary, to solve problems of their financing and realization. In this respect a real specialist in the field of nanoelectronics must possess a complex of knowledge: technical, economic, social and humanitarian which is based on the firm scientific and theoretical ground. Modern engineers in the field of nanoelectronics fulfill more and more administrative duties of an organizer, coordinator, manager of 
complex projects, head of scientific researches. Their professional activity needs human, technical and financial resources and often takes place in international environment, aimed at the benefits of society, where a great attention is paid to the protection of a person, life and environment (Bourn, 2008).

A present day engineer is a complete personality in the unity of their individual abilities, professional and social functions, as well as peculiar personal qualities. An engineer must possess a scientific outlook, engineering, technical and economic thinking, profound knowledge and deep humanitarian culture. In a normative model of an engineer the most important are their knowledge and abilities in various fields of science - fundamental, natural, technical, economic, philosophic, sociological, psychological, universal. Accumulation of this knowledge must continue at the production stage.

Technological needs of the global knowledge economics considerably change the essence of engineering education, demanding from a modern engineer in the field of nanoelectronics a much wider range of key competencies, than mastering narrow specializations of scientific, technical and engineering subjects.

Ever-increasing realization of importance of technological innovations in the field of nanoelectronics for competitiveness of economics demand new priorities for engineering activity. Close interaction and interrelation of fundamental and applied researches (even within some definite complex scientific and technical projects), interdisciplinary essence of new scientific nanotechnologies that give the possibility to solve complex tasks in traditional, adjacent and new fields demand new quality of engineering nanoeducation.

On the basis of cooperation of academic community and stakeholders there has been defined the reference point of engineering education development - implementation of global dimension into the content of engineering education that presupposes formation of global skills necessary for life and work in a globalized society (skills of corporate and social responsibility, entrepreneurial and social skills, skills of contextual analysis or STEEP (social, technical, economic, environment and political), professional, prognostic, communicative, of critical thinking etc.).

Implementation of global dimension into engineering profession comprises three aspects: generic themes (understanding global challenges, social responsibility, global interdependence of local and global), generic skills (holistic thinking, critical analysis and reflection, active learning and practical realization, self-consciousness and empathy, communication and understanding), generic dispositions (obligation to encourage social justice and responsibility, values and perception, entity and reliability, continuous development) (Bourn, 2008).

The strategy of implementing the global dimension into the content of engineering programs in nanoelectronics is primarily aimed at the development of an engineer personality at individual, national and global levels. Special attention is paid to moral qualities directed onto the fulfillment of the set tasks: enthusiasm, persistence, independence, endurance, restraint, politeness, ability to self-evaluation, self-analysis, high demands to oneself, high culture of human communication, tolerant interpersonal relations.

Academic community of engineering departments at Cambridge and Open Universities (H. Cruickshank, R. Fenner, P. Guthrie, B. Kennedy, A. Moncaster) is convinced that understanding global dimension must be the core of university life, its brand, strategy, structure, values and culture. Modernization of professional training of future engineers in the field of nanoelectronics must be carried out through the prism of global dimension in engineering education content and pedagogical innovations (Ainger, 2012; Fenner, 2012; Guthrie, 2010; Guthrie, 2014). 
Globalization of engineering education content presupposes, first of all, its fundamentalism and professionalization. Scientists are convinced that the main components of engineering education content in the field of nanoelectronics are:

- fundamental sciences that ensure the ability to clear analysis and skills to adapt to new demands of the profession;

- substantial professional knowledge in the field of nanoelectronics that ensure the effectiveness of a future specialist's work;

- the knowledge of corporate culture, understanding of the current economic situation, influence of social, human, ethical and philosophical factors of the environment and administrative skills;

- communicative skills; knowledge of the world culture traditions that encourage work on the basis of the obtained specialty; establishment of social contacts in any environment etc.

According to E. Bruun and I. Nelsen, the task of engineering nanoeducation is the provision of fundamentally trained competent specialists in the field of nanoelectronics, able to creatively apply in practice the newest achievements of nanoindustry, using innovative technologies and results of the science and techniques. Respectively, the formation of the content of professional training of future engineers in the field of nanoelectronics presupposes the creation of absolutely new fundamental subjects, aimed at the complete conception of the scientific representation of the world and the creation of the fundamental educational environment. Thus, it is aimed at: interrelation;

- the increase of general scientific subjects role and intensification of their

- transformation of the content of specialty subjects on the basis of concentration around the outlook and social problems with transition from analysis to synthesis of design solutions, their mathematical modeling and optimization;

- ensuring the formation of systemic thinking, methodological and informational culture (Bruun, 2010; Fenner, 2012).

Incorporation of the global dimension into the learning process of future engineers in the field of nanoelectronics encompasses five stages: the first stage is the substantiation of key skills that define global dimension in engineering education; the second one is the provision of connection between the results of learning and global dimension in engineering education; the third one is the determination of opportunities to realize global dimension (elaboration of new methods and approaches); the fourth stage is the integration of the learning content on the basis of consistency and interdisciplinary principles; the fifth one is the monitoring of learning results (Fig. 2).

\begin{tabular}{|c|c|c|c|c|}
\hline Stage 1 & Stage 2 & Stage 3 & Stage 4 & Stage 5 \\
\hline $\begin{array}{l}\text { Demands of } \\
\text { global } \\
\text { dimension in } \\
\text { engineering }\end{array}$ & $\begin{array}{l}\text { Connection } \\
\text { with the } \\
\text { learning } \\
\text { results } \\
\text { (UK SPEC) }\end{array}$ & $\begin{array}{l}\text { Collation of } \\
\text { learning results } \\
\text { and demands } \\
\text { of global } \\
\text { dimension }\end{array}$ & $\begin{array}{l}\text { Integration } \\
\text { of learning } \\
\text { content }\end{array}$ & $\begin{array}{l}\text { Monitoring } \\
\text { and evaluation } \\
\text { of learning } \\
\text { results }\end{array}$ \\
\hline
\end{tabular}

Fig. 2. Incorporation of global dimension into the learning process of future engineers in the field of nanoelectronics 
The first stage presupposes determination of the following key global skills: social (social responsibility for the consequences of one's activities, high level of spiritual and moral, social-psychological and physical culture, self-discipline, high intellectual level, professional mobility, readiness to intercultural interaction, aspiration to self-development, creative intuition, social activeness, moral values, knowledge of society laws); professional and administrative (projective, construction skills, skills of contextual analysis, self-control, critical and systemic thinking, creative and conceptual skills, skills of a team work, communicative skills, adaptation); ecological ("life" skills, skills of constant development, skills of bio resources administration); entrepreneurial (business opportunities, business ethics, corporate responsibility, conflict solving culture, organizational abilities). Formation and development of the mentioned skills take place in the course of studying compulsory and optional (elective) subjects (modules), carrying out group and interdisciplinary projects. Flexibility of the programs is ensured with the possibility to choose not only different courses, but their separate parts. Successful professional activities of a modern engineer in the field of nanoelectronics presuppose social responsibility and intellectual honesty, developed humanistic outlook. Thus, the elaboration of the content of nanoengineers' training presupposes mastering professional ethics as a compulsory component of formation of their professional competence on the basis of modern philosophy of engineering education.

The second stage is focused on establishing interrelation and collation of learning results and demands of global dimension. Substantiation of the criteria and indicators of the professional competence of future engineers in the field of nanoelectronics formation is provided according to current educational standards in the field of engineering.

It should be mentioned that the main feature of the global dimension is, primarily, the practical realization of the gained knowledge, ability to transform it into innovative technologies, adapt it to global needs, fully synthesize scientific knowledge with achievements of other sciences. In their combination the defined abilities provide possibilities to realize some definite professional functions, namely: analytical, orientation, prognostic, modeling, system-forming, of scientific research. The total content of professional competence of a future engineer in the field of nanoelectronics gives possibility to affirm that it is formed in the process of specialists' productive activities aimed at enrichment and development of a global knowledge system with the help of objective and systemic analysis of the environment.

The third stage presupposes substantiation and determination of possible directions of the global dimension realization in the content of engineering education. Among the directions the following should be defined: modernization of educational program (adherence to ethical and moral values expressed in the content, flexibility of the program (compulsory and elective subjects), compulsory lectureships, technical-economic and design projects, dissertations and scientific-research projects, focusing on the development of entrepreneurial and administrative skills, introduction of innovative pedagogical technologies of learning), development of social partnership (relations of schools, departments, graduates, research centers; partnerships with foreign campuses and universities in the developing countries), diversification of professional development forms (informal education), institutionalization of engineering education (post-graduate courses, short-termed learning courses, centers for career development, centers for sustainable development, process of updating and modernization of educational programs and curricula, monitoring of engineering education quality), internationalization of engineering education (experience exchange, accreditation, international cooperation and initiatives).

The fourth stage is aimed at interdisciplinary integration of engineering training content on the basis of consistency and interdisciplinary principles. Innovations in 
techniques and technologies are formed, as a rule, on multidisciplinary basis as the result of using knowledge in different scientific branches, and with every generation innovations become more and more scientifically-based. Combination of fundamental and applied knowledge, modern technologies and, the most important, their effective practical use is the main task of an engineer in their innovative activities.

Monitoring of learning results is carried out at the fifth stage. Due to analysis of ways to monitor the quality of future nanoelectricians' professional training the following levels of this process have been outlined: internal (current, modular, final control of knowledge, questioning) and external (accreditation, certification).

\section{CONCLUSIONS}

Generalization of the research results makes it possible to conclude that the basis of conceptual approaches to engineering training of future specialists in the field of nanoelectronics is the logics and the content of the "engineer" notion, specifics of engineering activities in the field of nanoelectronics, as well as their functional duties in the context of globalization challenges. The main reference point is the formation of global skills of an engineer-nanoelectrician. The process of introduction of the global dimension into the content of engineering programs in nanoelectronics encourages the development of an engineer's personality at all the levels - individual, national and global.

Prospects of further research concern the analysis of global dimension application for ensuring effective professional training of engineers in the field of nanoelectronics at the national and international levels.

\section{REFERENCES}

1. Ainger, C., Cruickshank, H., \& Fenner, R. (2012). Graduate education for leadership and organisational change in sustainable development. International Conference on Innovation, Practice and Research in Engineering Education, Conference Proceedings. UK: Loughborough University.

2. Bourn, D., \& Sharma, N. (2008). Global and "Sustainability Perspectives within engineering”. The Municipal Engineer, 161 (3), 129-135.

3. Bourn, D., \& Neal, I. (2008). The Global Engineer. Incorporating global skills within UK higher education of engineers. London: DFID.

4. Bruun, E., \& Nielsen, I. (2010). A model for the development of university curricula in nanoelectronics. European Journal of Engineering Education, 35 (6), 655-666.

5. Fenner, R., \& Cruickshank, H. (2012). Exploring key sustainable development themes through learning activities. International Journal of Sustainability in Higher Education, 13, 249-262.

6. Guthrie, P., Cruickshank, H., \& Moncaster, A. (2010). Knowledge exchange between academia and industry. Proceedings of the Institution of Civil Engineers Engineering Sustainability, 163 (3), 167-174.

7. Guthrie, P., Opoku, A., Cruickshank, H., \& Georgiadou, M. (2014). Stakeholder engagement in research: The case of retrofit 2050 research project. Sustainable Development. Proceedings of the 30th Annual Association of Researchers in Construction Management Conference. UK: Association of Researchers in Construction Management. 